\title{
Simulation-Based Trucks Configuration for Twin 40 Feet Quay Cranes in Container Terminals
}

\author{
Peng Yun, Wang Wenyuan, Zhang Qi, Chen Modi, and Zhang Ran
}

\begin{abstract}
Twin 40 feet quay cranes are used to improve handling efficiency in container terminals. However, the recommended value of container trucks number is not given in national norms. After discussing the operating characteristics of the twin 40 feet quay cranes, a microscopic traffic simulation model is built for a container terminal with twin 40 feet quay cranes in Dalian to research for trucks configuration problem. Container terminal apron, yard and port gate area are included in this model. By running the simulation model, the traffic operation rule in container terminals with twin 40 feet quay cranes and the relationship between container trucks number and the average handling efficiency of twin $\mathbf{4 0}$ feet quay cranes can be observed. Lastly, the suggestion of optimal numbers of container trucks are given, which can provide experience and reference for container terminals planning with twin 40 feet quay cranes.
\end{abstract}

Index Terms - Container terminals, twin $\mathbf{4 0}$ feet quay cranes, trucks configuration, traffic simulation.

\section{INTRODUCTION}

With the growing influence of global economic integration, coastal port container business showed a trend of rapid growth, "Maersk. Mike Kinney. Muller" container ship has input operations in the Asia Europe routes, declared that we have entered the era of 18000 TEUs container transportation in the world. In order to adapt to the trend of large ships, part of the domestic large-scale container port, such as port of Shanghai Yangshan Port, began to applying twin 40 feet quay cranes for wharf loading and unloading operations gradually. In theory, twin 40 feet quay cranes can load and unload two 40 foot containers at the same time. The single handling efficiency should be $50 \%$ higher than ordinary bridge crane, however, the actual use of the situation is not ideal [1], one of the important reasons is the lack of harbor container truck it lead to effective convergence and coordination problems between horizontal transportation system and twin 40 feet quay cranes. The problem of truck in container terminal mainly includes two aspects, one is container truck dispatch in operation period, and the other is planning of container truck configuration. Foreign scholars mainly focus on optimization scheduling and strategy of truck in the terminal operation period. L H Lee et al.. [2] established a mathematical model to study the container hub port of the vehicle scheduling algorithm based on the mixed integer programming, genetic algorithm and the minimum; Li X et al.. [3] studied the

Manuscript received June 28, 2016; revised August 13, 2016. This work was supported in part by the Natural Science Foundation of China.

The authors are with the Faculty of Infrastructure Engineering, Dalian University of Technology, China (e-mail: yun_peng@yahoo.com, wangwenyuan@dlut.edu.cn, chenmd@mail.dlut.edu.cn, zhangran.dlut@foxmail.com). vehicle routing problem in the harbor by considering the random choice of travel time and path of the vehicle; Lee D et al. [4] studied the scheduling and yard allocation problems based on heuristic algorithm; In addition, there are some scholars put forward the truck appointment system, internal container trucks sharing system and so on to improve the operating efficiency of the port container truck [5], [6]; Domestic scholars pay more attention to study truck configuration and the research is more suitable for engineering practice in our country. De Peng Liu [7] established a simulation model based on evolutionary theory and genetic algorithm which can get the reasonable number of container truck in maintain crane with little change and with the minimum truck service time as the optimization objective; Jinglei Yang et al. [8] took Shanghai Waigaoqiao container terminal as an example, analyzing the optimal mechanical ratio and optimal number of quay cranes through establishing dynamic queuing multiclass network with anchorage area, berth, quay cranes, gantry crane and container trucks included; Shaokai Zhang et al. [9] established a operation simulation model of container trucks to analyze the impact of handling equipment configuration on port operation under new and old handling technology, providing a reference for handling equipment configuration under different strategies. However, the existing research about container terminal with twin 40 feet quay cranes is poor [10], [11], while these few studies concentrated on optimization algorithm of container trucks during the operating time, lacking the establishment of system simulation model, and lacking recommendations on container truck configuration during ports layout.

This paper takes a large scale container terminal in Dalian as an example, establishing a microscopic traffic simulation model for container terminal with twin 40 feet quay cranes through using simulation software VISSIM, on the basis of analyzing the operating characteristics of twin 40 feet quay cranes. By running the simulation model, the traffic operation rule in container terminals with twin 40 feet quay cranes is discussed, and then based on the mean delay of container trucks under quay cranes and field bridges, analyzing the impact of container trucks number allocated on twin 40 feet quay cranes on the traffic conditions in container terminal. On the whole, this paper makes some contributions to the rational container truck configuration of twin 40 feet quay cranes during the container terminal layout.

\section{Operating Characteristics OF Twin 40 FEET QuAY CRANES}

The main difference between twin 40 feet quay cranes and single 40 quay cranes commonly used at present is that, the twin 40 feet quay crane has two independent lifting devices, and with the synchronization coordinated control on them, 
two 40 feet containers could be lifted at the same time every lifting operation. Single 40 quay cranes need to position the container 2 times in a lifting operation cycle, while twin 40 feet quay cranes require the operators to position the containers 4 times [12]. Thus, as shown in the Fig. 1, compared with the single 40 quay cranes, one operating cycle of twin 40 feet quay crane consumes more time of 2 times positioning, locking, and decoupling containers.

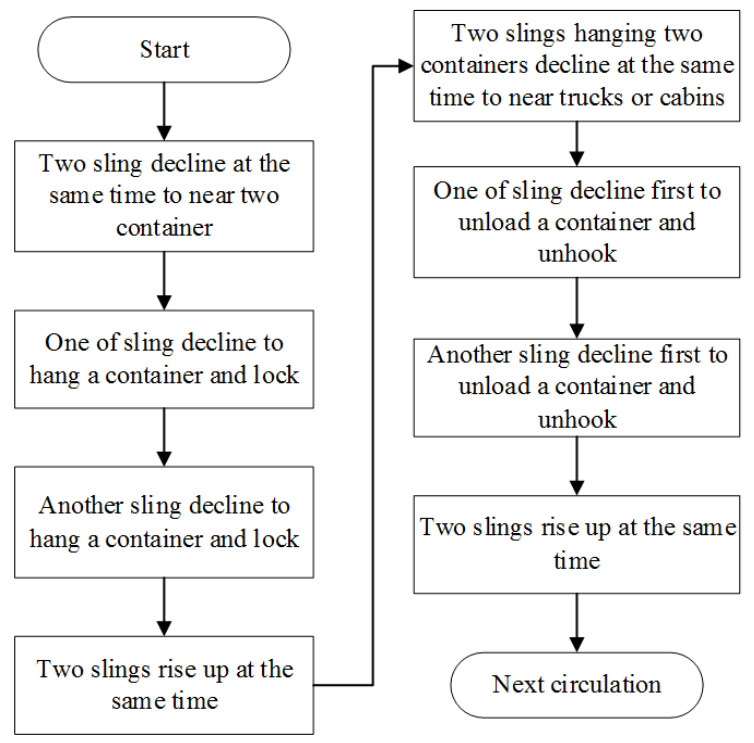

Fig. 1. One lifting operation of twin 40 feet quay crane.

In contrast to the common single 40 feet quay cranes, the terminal apron traffic conditions during the handling operation of twin 40 feet quay cranes are more complicated. On one hand, because of more container trucks and longer time of single lifting operation, the queue length of container trucks under twin 40 feet quay cranes is larger, which greatly hinders the container trucks at terminal apron and behind the quay cranes from leaving terminal apron. On the other, the operation points number of single quay crane increases from 1 to 2 , as a result, more complicated lane-changing driving state will be carried out by container trucks, resulting in an increase in lane-changing interference. Influence of both aspects' interruption has more negative effect on the coordinative operation of the plane transportation system and the twin 40 feet quay cranes, and hence limiting the full play of twin 40 feet quay cranes.

\section{SyStem SimUlation MODELING}

Taking one of the container ports in Dalian as the prototype, a container port land microscopic traffic system simulation model for twin 40 feet quay cranes is built in order to set the travel path in port, parameter distribution and performance parameters of the container trucks in accordance with twin 40 feet quay cranes handling technology and the actual situation. In addition, the simulation model achieves holistic modeling of production operations in port and traffic operation, then a complete road transport network is established not only to reflect the path selection of the container trucks in the process of production operations in port from the macro level, but also simulate the microscopic traffic characteristics of the container trucks in port effectively such as following, lane changing and overtaking from the micro level.

\section{A. Establishment of Model Road Network}

The trucks configuration of twin 40 feet quay cranes on the one hand should fit the land arrangement and job line layout of the specific container terminals, on the other hand should also match the actual situation of the road layout in port in container terminals, the paper takes a container terminal in Dalian as an example with its plane layout shown in Fig. 2 and working point arrangement of twin 40 feet quay cranes at the front of quay shown in Fig. 3.

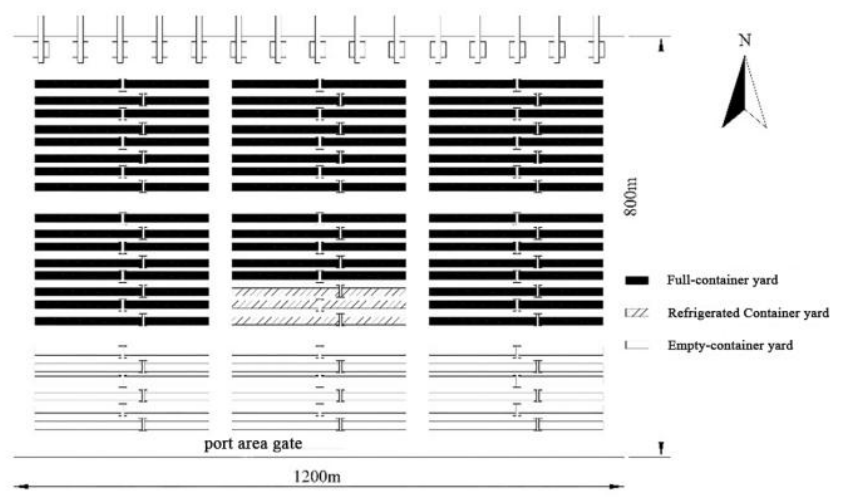

Fig. 2. Container terminal plane layout.

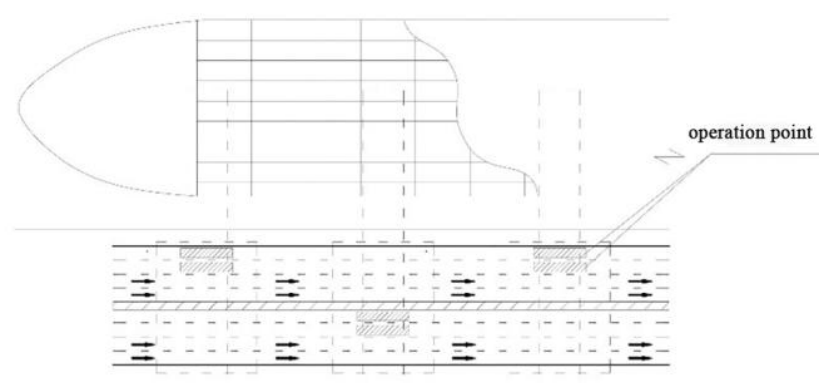

Fig. 3. Operation points layout under twin 40 feet quay cranes.

The Terminal Shoreline of the container terminal in Dalian is $1200 \mathrm{~m}$ length and the land depth is $800 \mathrm{~m}$, while the front of quay is equipped with 15 twin 40 feet quay cranes and the yard area with 66 Rubber-typed gantry cranes. Within the port area including eight main roads of "four vertical and four horizontal", one quay crane operation channel and 66 gantry crane operation channels( one gantry corresponds to one operation channel ). What's more, the eight main roads are all two-way six lanes, while the quay crane operation channel is one-way eight lanes which is centered in isolation, divided into two operation channels of four lanes which have the same direction. Meanwhile, in order to ensure a high traffic efficiency of the container trucks under the quay crane, the working points of twin 40 feet quay cranes are staggered arrangement.

\section{B. Model Basic Setting}

1) Travel path and parameter distribution.The driving route of the container trucks is designed according to the handling technology of twin 40 feet quay cranes : after entering from the port gate, the container trucks outside the port head for the corresponding heavy container, empty container or refrigerated container yards according to their job schedule, then wait for lifting operation under the quay cranes, in the end leave the port gate after completing the lifting 
operation; the container trucks inside the port set out from the container truck parking field(near the port gate) towards the front of the quay, then wait for lifting operation in line under the quay cranes, after a complete lifting operation cycle they head for the corresponding heavy container,empty container or refrigerated container yards randomly, then wait for lifting operation in line under the quay cranes of the corresponding yards, after completing the lifting operation they head for the front of quay again.

From investigation, handling time of the container trucks at gantry crane follows Normal distribution with the average value of $120 \mathrm{~s}$ and the standard deviation of $5 \mathrm{~s}$. Because of the complexity of the handling technology of twin 40 feet quay cranes at the front of quay, this study adopts VAP module coming with VISSIM to realize the release control before the container trucks arrive in the working points of twin 40 feet quay cranes by sensing signal control, after release the container trucks enter the working points of twin 40 feet quay cranes to start lifting. However, currently the survey data of the time to complete one lifting operation of twin 40 feet quay cranes is not sufficient, therefore, the paper launch five sets of parallel tests with the time of single lifting operation of twin 40 feet quay cranes called T for 80 s, 100 s, 120 s, 140 s, 160 s to execute microscopic traffic simulation of land area in port with different container trucks configuration respectively.

According to the historical investigation data, the arrival time to reach the port gate of the container trucks outside the port is basically in accord with Poisson distribution and the through capacity of entry gate of port is 240 vehicles per hour.

2) Container truck performance and driving behavior parameters. The target speed of container trucks running in port is $20 \sim 35 \mathrm{~km} / \mathrm{h}$ and its main performance parameters are shown in Table 1 . In order to objectively reflect the actual traffic conditions, driving behavior parameters in model should be calibrated correctly. The selection of car following model in this paper is Wiedemann 74 model and the selection of free lane for lateral movement rules which allows the vehicle to overtake in any lane, while the calibration value of car following parameters and lane changing parameters of the container trucks after correction are shown in Table II [13].

TABLE I: MAIN TRUCK PERFORMANCE PARAMETERS

\begin{tabular}{ccccccc}
\hline Length $/ \mathrm{m}$ & Width/m & Weight $/ \mathrm{kg}$ & $\begin{array}{c}\text { Maximum } \\
\text { acceleration } \\
/ \mathrm{m} \cdot \mathrm{s}^{2}\end{array}$ & $\begin{array}{c}\text { Expect } \\
\text { acceleration } \\
/ \mathrm{m} \cdot \mathrm{s}^{-2}\end{array}$ & $\begin{array}{c}\text { Maximum } \\
\text { deceleration } \\
/ \mathrm{m} \cdot \mathrm{s}^{2}\end{array}$ & $\begin{array}{c}\text { Expect } \\
\text { deceleration } \\
/ \mathrm{m} \cdot \mathrm{s}^{2}\end{array}$ \\
\hline 16.0 & 2.5 & $23000-58000$ & 1.3 & 0.8 & -5.5 & -1.3 \\
\hline
\end{tabular}

TABLE II: MAIN TRUCK DRIVING BEHAVIOR PARAMETERS

\begin{tabular}{ccccccc}
\hline \multicolumn{2}{c}{ Car following parameters } & & \multicolumn{3}{c}{ Lane changing parameters } \\
\hline $\begin{array}{c}\text { Average } \\
\text { parking } \\
\text { distance } / \mathrm{m}\end{array}$ & $\begin{array}{c}\text { Additional } \\
\text { part of } \\
\text { safety } \\
\text { distance } / \mathrm{m}\end{array}$ & $\begin{array}{c}\text { Multiple } \\
\text { part of } \\
\text { safety } \\
\text { distance/ } / \\
\mathrm{m}\end{array}$ & $\begin{array}{c}\text { Maximum } \\
\text { deceleration } \\
/ \mathrm{m} \cdot \mathrm{s}^{-2}\end{array}$ & $\begin{array}{c}\text { Acceptable } \\
\text { deceleration } \\
/ \mathrm{m} \cdot \mathrm{s}^{-2}\end{array}$ & $\begin{array}{c}\text { Minimum } \\
\text { front free } \\
\text { distance } / \mathrm{m}\end{array}$ \\
\hline 2.00 & 2.75 & 3.75 & -4.20 & -1.30 & 0.50 \\
\hline
\end{tabular}

\section{Simulation Results Analysis}

By running the microscopic traffic simulation model of a container terminal in Dalian, the traffic operation rule in container terminals with twin 40 feet quay cranes can be observed: when a large vessel being handled, the large yard and port automation management have distracted the yard traffic pressure largely, which causing from handling the vessel. Corresponding to this, the operation points planning and handling technology of twin 40 feet quay cranes are more complicated. Thus, container trucks are always gathering at the terminal apron inevitably, which makes the terminal apron traffic bottleneck when handling the large vessel.

\section{A. The Impact of Layout Quantity on Average Delay Time under Quay Crane of Container Truck}

The mean delay under quay crane of container truck $t_{1}$ is used as the judgment basis to the traffic conditions at the terminal apron. The relationship between the average delay time $t_{1}$ and container trucks number $\mathrm{n}$ is shown in Fig. 4.

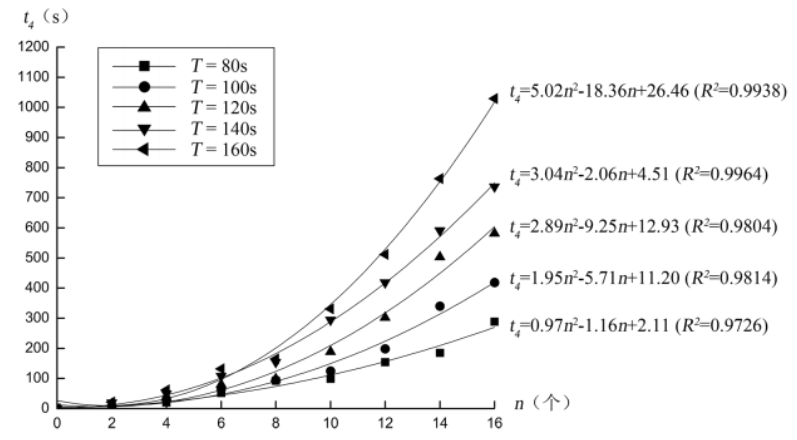

Fig. 4. Relationship between average container trucks number and average handling efficiency of twin 40 feet quay cranes.

As clearly shown that to this container terminal:

1) As the layout quantity of container truck increases, the average delay time under quay crane increases gradually.

2) When the container trucks number of single twin 40 feet quay cranes is less than or equal to 8 , the average delay time under quay crane increases slowly, and when it is more than 8 , the delay time increases relatively fast. As to the 40 feet quay cranes whose single lift operation time is 120 s, the average delay time under quay crane of container trucks has exceeded 500s, up to 4.2 times the single lift operation time of quay cranes, and because of this, it has obvious impact on the traffic conditions at the terminal apron and the handling efficiency of twin 40 feet quay cranes.

3) The quadratic function is adopted to fit the relationship between the average delay time under quay crane and the layout quantity of container trucks, the results show that: the fitting degrees of 5 parallel tests are all over 0.97 , from which we can assume that there is a quadratic function relationship between $t_{1}$ and $n$.

4) The quadratic function is adopted to fit the relationship between the average delay time under quay crane and the layout quantity of container trucks, the results show that: the fitting degrees of 5 parallel tests are all over 0.97 , from which we can assume that there is a quadratic function relationship between $t_{1}$ and $n$.

\section{B. The Impact of Layout Quantity on Average Delay Time under Field Bridge of Container Truck}

The mean delay under field bridge of container truck $t_{2}$ is used as the judgment basis to the traffic conditions inside the yard. The relationship between the average delay time $t_{2}$ and container trucks number $\mathrm{n}$ is shown in Fig. 5. 


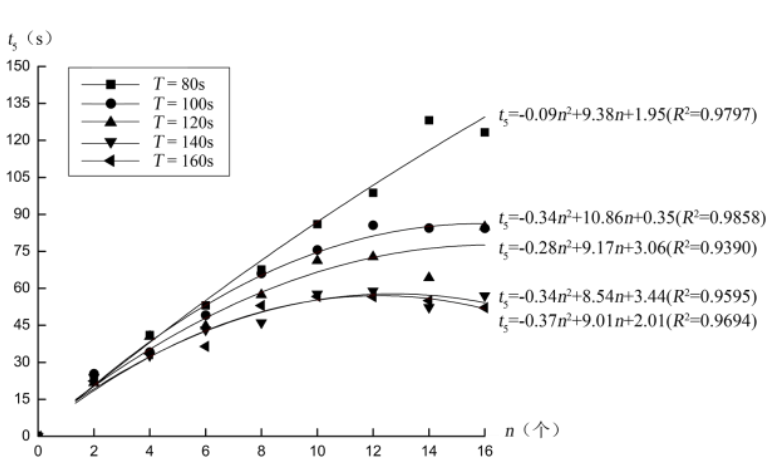

Fig. 5. Relationship between average container trucks number and mean delay under field bridge.

1) Through the comparative analysis between the simulation results of Fig.4 and Fig.5, the ratio of the average delay time under field bridge and quay crane is achieved. The results show that: when the container trucks number is determined, almost all the ratio values are no more than 1:10. Thus, when compared with the average delay time under quay crane $t_{1}$, the container trucks number has less impact on the average delay time under field bridge $t_{2}$, that is to say, it has less impact on the yard traffic conditions. One reason is that, in contrast to the operation space of container terminal apron, yard operation space is relatively broad. For another, the mean delay of container trucks under field bridge is affected by container trucks both inside and outside the port.

2) The arrival interval distributions and route selection of container trucks outside the port are with strong randomness, and the relationship between the mean delay of container trucks under field bridge and the container trucks number is not very obvious. This paper still use the quadratic function to fit the relationship, and the obtained fitting degrees of 5 parallel tests are all over 0.93 , from which we can assume that there is a quadratic function relationship between $t_{2}$ and $n$.

\section{CONCLUSION}

This paper analyzes the operating characteristics of twin 40 feet quay cranes first, and then take a container terminal in Dalian as an example, builds a microscopic traffic simulation model for container terminal with twin 40 feet quay cranes, with container terminal apron, yard and port gate area included, through using simulation software VISSIM. Based on this simulation model, 5 parallel tests with different single lift operation time of twin 40 feet quay cranes $(80 \mathrm{~s}, 100 \mathrm{~s}, 120 \mathrm{~s}$ $140 \mathrm{~s}$, and 160s, respectively) were carried out. The study showed that, the relationship between the number of container trucks allocated on twin 40 feet quay cranes and the average delay time under quay crane or field bridge is a quadratic function. When the number of container trucks is more than or equal to 14 , the mean delay of container truck under quay crane reaches 4.2 times the single lift operation time of quay cranes, which makes great impact on the traffic conditions at the container terminal apron. When the container trucks number is determined, the ratio values of the average delay time under field bridge and quay crane of container trucks mainly don't exceed 1:10, and the results showed that it has relatively small impact on the yard traffic conditions. This paper makes some progress in the truck configuration study for twin 40 feet quay cranes of container terminals, and provides a good reference and experience for the ports planning of container terminal with twin 40 feet quay cranes, especially the container truck configuration.

\section{REFERENCES}

[1] B. Qifan and J. Maohai, "Twin 40 feet quay cranes' application," Containerization, 2008, vol. 2, pp. 1-4.

[2] L. H. Lee, E. P. Chew, K. C. Tan et al., "Vehicle dispatching algorithms for container transshipment hubs," OR Spectrum, 2010, vol. 32, no. 3, pp. 663-685.

[3] X. Li, P. Tian, and S. C. H. Leung, "Vehicle routing problems with time windows and stochastic travel and service times: Models and algorithm," International Journal of Production Economics, 2010, vol. 125 , no. 1 , pp. 137-145.

[4] D. Lee, J. X. Cao, Q. Shi et al., "A heuristic algorithm for yard truck scheduling and storage allocation problems," Transportation Research Part E: Logistics and Transportation Review, 2009, vol. 45, no. 5, pp. 810-820.

[5] E. Zehendner and D. Feillet, "Benefits of a truck appointment system on the service quality of inland transport modes at a multimodal container terminal," European Journal of Operational Research, 2014, vol. 235, no. 2, pp. 461-469.

[6] J. He, W. Zhang, Y. Huang et al., "A simulation optimization method for internal trucks sharing assignment among multiple container terminals," Advanced Engineering Informatics, 2013, vol. 27, no. 4, pp. 598-614.

[7] L. Depeng, "The traffic organization and reasonable collocation of equipments in logistic system of container port," Wuhan: Wuhan University of Technology, 2006.

[8] J. L. Yang and Y. Zhong, "Ding study on the simulation of a dynamic multilevel queuing network for container terminals," Journal of System Simulation, 2003, pp. 1069-1073.

[9] S. K. Zhang, X. L. Han, and S. L. Hu, "Simulation of equipment allocation under two different handling technologies," Journal of Guangxi University (Natural Science Edition), 2013, vol. 2, pp. 368-373.

[10] J. J. Wu, "The study of trucks dispatching for twin 40 feet quay Cranes in container termianls," Logistics Engineering and Management, 2015, vol. 3, pp. 97-100.

[11] S. Jin, "Vehicle routing model and algorithm for twin $40 \mathrm{ft}$ quay cranes in container termianls," Journal of Huazhong University of Science and Technology (Natural Science Edition), 2010, vol. 38, no. 11, pp. pp. 84-87.

[12] Z. Bin, F. H. Wu, M. H. Fu, and D. M. Chen, "Handling technology of dual 40 feet containers' quayside container crane," Port \& Waterway Engineering, 2005, vol. 5, pp. 70-73.

[13] Z. Z. Wu, Y. J. Fan, and J. Q. Zhang, "Model of merge capacity under impact of container trucks," Journal of Tongji University(Natural Science), 2015, pp. 670-675.

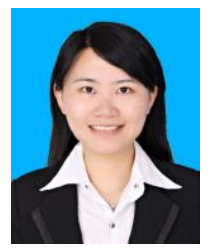

Peng Yun was born in Tieling, Liaoning province on November 16th, 1988. Peng studied waterway and coastal engineering as an undergrad in Tianjin University from 2006 to 2010. After graduating Peng studied coastal and offshore engineering in Dalian University of Technology from 2010 to 2013. From 2013 to 2015, Peng majored in civil and environmental engineering in Harbor in University of California, Davis and got a doctor of philosophy. Now, she as a lecturer is working in the Faculty of Infrastructure Engineering, Dalian University of Technology, China. She published 15 papers, which 5 articles published by SCI journal.

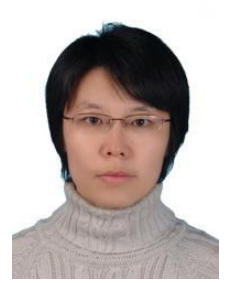

Wang Wenyuan was born in Fuxin , Liaoning province on January 4th, 1984. Wang studied waterway and coastal engineering in Dalian University of Technology from 2002 to 2012. In 2012, Wang got a doctor of philosophy in Harbor Now, she as a lecturer is working in the Faculty of Infrastructure Engineering, Dalian University of Technology, China. She has 2 copyright such as An Ecological Barrier Board and oastal Fairway and Anchorage Design Aided Analysis System She has awarded "Research on Reasonable Throughput of Coastal Container 
Terminal", Third Prize of Science and Technology of China Water Transportation Construction Association, 2012

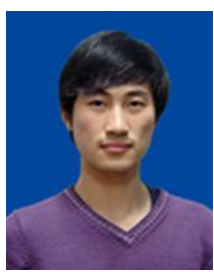

Zhang Qi was born in Zhengzhou, Henan province on October 11th, 1989. Zhang studied waterway and coastal engineering as an undergrad in Southeast University from 2008 to 2012. After graduating Zhang studied Coastal and Offshore Engineering in Dalian University of Technology from 2012 to now. His main research areas are port planning and layout, port transportation planning and port management.

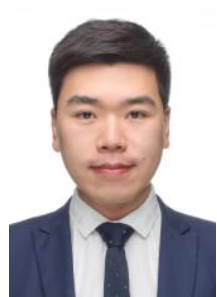

Chen Modi born in Changchun, Jilin province on January 1th, 1992. Chen studied waterway and coastal engineering as an undergrad in Dalian University of Technology from 2010 to 2014. After graduating Chen is studying coastal and offshore engineering in Dalian University of Technology.

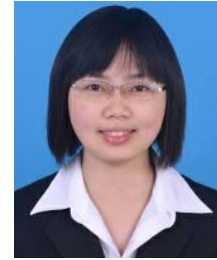

Zhang Ran born in Xinyang, Henan province on July 4th, 1991. Zhang studied waterway and coastal engineering as an undergrad in Dalian University of Technology from 2012 to 2015. Now, she is working in the China Design Group. 